\title{
Multidisciplinary Team Approach in Patient Management Mandates Inclusion of Interprofessional Education in Curriculum
}

\author{
Shivali Shamsher ${ }^{1}$, Thiagarajan Praba ${ }^{2}$, Koyalmannam Raman Sethuraman ${ }^{3}$, Shilpa Shamsher ${ }^{4}$
}

\begin{abstract}
Health care today incorporates the multidisciplinary team approach for holistic patient management in every discipline. It necessitates the inclusion of interprofessional education (IPE) in the medical education and training system to equip future doctors to adapt it for better patient outcomes. This article aims to draw attention of the stakeholders and policymakers toward the role of IPE in the medical curriculum.
\end{abstract}

Keywords: Health professions, Interprofessional education, Medical curriculum, Multidisciplinary management, Team approach. SBV Journal of Basic, Clinical and Applied Health Science (2021): 10.5005/jp-journals-10082-03120

\section{INTRODUCTION}

Improvement in patient care is the goal of the medical health professional education remodeling. Managing patient as an individual and not the disease is the crux of the holistic approach to management in patient care. A holistic approach includes dealing with the effects of the illness on the patients' all spheres of life, including physical, mental, and social well-being. While preparing the professionals of tomorrow, it is vital to inculcate in them the importance of a collaborative multidisciplinary team in patient care.

\section{What is Interprofessional Education?}

Various definitions of interprofessional education (IPE) exist. The American Association of Colleges of Pharmacy-Interprofessional Education Task Force ${ }^{1-4}$ definition reads as "Interprofessional education involves educators and learners from two or more health professions and their foundational disciplines who jointly create and foster a collaborative learning environment. The goal of these efforts is to develop knowledge, skills, and attitudes that result in interprofessional team behaviors and competence. Ideally, IPE is incorporated throughout the entire curriculum in a vertically and horizontally integrated fashion."

\section{WhAT IS NOT IPE?}

To have a clearer picture, it is equally important to understand what is not considered IPE. ${ }^{4}$ Students from different health professions who are unable to interact actively and gain but are physically in the same classroom and receiving the same knowledge or having the same learning experience are not considered IPE. ${ }^{4,5}$

An educator from a different profession teaching the subject without explaining the interprofessional correlation and patientcentered relevance is not considered IPE.

Another example is a patient care setting, which has various healthcare professionals but without shared responsibility or equal power in decision making in the patient care..$^{1-4}$
${ }^{1,2}$ Anaesthesia Unit, Faculty of Medicine, Asian Institute of Medicine,
Science and Technology University, Bedong, Kedah, Malaysia
${ }^{3}$ Medicine and Medical Education, Faculty of Medicine, Asian Institute
of Medicine, Science and Technology University, Bedong, Kedah,
Malaysia
${ }^{4}$ Surgical Unit, The Queen Elizabeth Hospital, Woodville South, South
Australia, Australia
Corresponding Author: Shivali Shamsher, Anaesthesia Unit, Faculty
of Medicine, Asian Institute of Medicine, Science and Technology
University, Bedong, Kedah, Malaysia, Phone: +60126987687, e-mail:
shivalibernard@gmail.com
How to cite this article: Shamsher S, Praba T, Sethuraman KR,
Shamsher S. Multidisciplinary Team Approach in Patient Management
Mandates Inclusion of Interprofessional Education in Curriculum.
J Basic Clin Appl Health Sci 2021;4(4):87-89.
Source of support: Nil
Conflict of interest: None

\section{What is the Goal of IPE?}

The IPE aims to educate the medical students to approach the management of the patients keeping all aspects of the patient's life in mind. The professionals need to know and understand the individual well, their needs, and the effects of the illness on individuals' all spheres of life. ${ }^{6}$ All this is in addition to the knowledge of the disease itself.

IPE improves the patient outcome as it teaches interprofessional patient care. ${ }^{4,5}$ It teaches the students to work as interprofessional team in their future practice. IPE team encompasses members specializing in different disciplines working together for patientcentered care. Each team member is empowered to decision plan depending on their expertise as the joint decision is valued. ${ }^{3,4}$

\section{WHY IPE?}

The 2006 to 2007 task force listed out the competencies and objectives of IPE after reviewing the literature. ${ }^{2-5,7}$ Vital competencies

(c) The Author(s). 2021 Open Access This article is distributed under the terms of the Creative Commons Attribution 4.0 International License (https://creativecommons. org/licenses/by-nc/4.0/), which permits unrestricted use, distribution, and non-commercial reproduction in any medium, provided you give appropriate credit to the original author(s) and the source, provide a link to the Creative Commons license, and indicate if changes were made. The Creative Commons Public Domain Dedication waiver (http://creativecommons.org/publicdomain/zero/1.0/) applies to the data made available in this article, unless otherwise stated. 
like "teamwork, communication skills, team organization and function, assessing and enhancing team performance, intrateam and interteam communication, leadership, resolving conflict and consensus building, and setting common patient care goals can be achieved by collaborative interprofessional education". ${ }^{4}$

Various professional bodies have included IPE in their accreditation standards and guidelines. ${ }^{4,8-11}$ As far as medical education is concerned, "there are no official accreditation standards about IPE specifically in medical education". 4,9 Nevertheless, it becomes the need of the hour to include IPE in the curriculum to move toward holistic care of the patient.

\section{Example of Interprofessional Education in Practice}

The Local Clinical Practice Guidelines (CPG) ${ }^{12}$ on the management of diabetes enforce the holistic approach to the management of diabetes. The multidisciplinary team involved in the management of diabetic patients includes primary care practitioner, diabetes educator, dietitian, physician, endocrinologist, pharmacist, optometrist, ophthalmologist, oral health professional, and physiotherapist.

The medical education IPE plan on diabetes includes the basic knowledge of the disease and complications, better understanding of the patients and their lifestyle, and the effects of the disease on the lifestyle. This helps in making the lifestyle modifications more practical, thus individualizing the management plan. Nonclinical, paraclinical, and clinical medical professionals impart the knowledge of the disease and complications and its effects on the patient's lifestyle. The dietitian teaches the individualized diet plan and its co-relation to the lifestyle modification. The physiotherapist's focus is on the individualized exercise plan, which is practical and possible for the patient. These patients may have other comorbidities like obesity, arthritis, and cardiovascular diseases. The pharmacist educates on the relevance of compliance, issues like polypharmacy, side effects of drugs, etc. The dentist highlights the dental complications and need of reference for regular dental checkups. The Nursing care professionals emphasize the nursing care of the diabetic patient.

Last but not the least the Anaesthesiologist highlights the special considerations of the controlled and uncontrolled diabetic patient coming for surgery, and the intensivist and emergency physician embark on the life-threatening emergencies like diabetic ketoacidosis.

The core of the IPE is patient-centered. The patient needs to understand the disease and its complications, accept the responsibility of self-care, and the necessity of management. Diabetes Educator and all the professionals educate the patient as well as the family. Good communication with the patient, family members, and among professionals involved in the patient management is vital. It avoids confusion, and the plan remains consistent.

Good communication skills help to form a good rapport with the patient. Good rapport helps in building trust. The patients are more likely to follow the advice if they trust the professional. The more the contact time between the educator and the patient, the better is the outcome. ${ }^{12}$

IPE teaches the students to function as a team to improve patient outcomes and practice it in their career.

The interprofessional collaboration success depends on the administrative facilitation. The where, when, and who questions require strategic planning to be answered. Starting from time and personnel resources to infrastructure and financial resources, each step requires individual and team support agreed upon by the administration. The planning of the yearly schedule will require inclusion of the IPE in the schedule of all the facilities concerned and allotment of the appropriate lecture halls and interprofessional communications and relations. ${ }^{4}$ The best time to introduce IPE into the undergraduate curriculum is still under debate, and a recent Swiss study recommends an early introduction of IPE in the medical curriculum. ${ }^{13}$

\section{How to Assess IPE?}

To make it effective, assessment must be an integral component of IPE sessions. Participant experience could be elicited using an online feedback template. Pretest and posttest would give evidence of gain in knowledge. Attitude assessment is an important component of IPE for which a validated Interprofessional Attitudes Scale (IPAS) is available. ${ }^{14}$

IPAS evaluation is based on the assessment of attitude toward the vital competencies of IPE, such as teamwork, communication skills, mutual respect, practical patient problem solving, and consensus-building for common patient care goals, taking into consideration the multidisciplinary collaboration.

"Interprofessional team-based case challenge" would be an exciting way to engage students in IPE exercises with the focus on fast-action in emergency case scenarios and critical thinking and collaborative problem-solving in complex case scenarios. The assessment will be for each team and not for an individual.

\section{What are the BarRiers to the IMPLEMENTATION OF IPE?}

Successful implementation of IPE faces barriers at various steps starting from organization-level down to faculty and student level. The main barriers identified in a Canadian study ${ }^{15}$ and American study ${ }^{16}$ were "scheduling, rigid curriculum, 'turf battles,' and lack of perceived value to IPE and attitudinal differences in health professionals, faculty members, and students, respectively". ${ }^{4}$

It is vital to understand that as the health care advances, it is essential to modify the education and training of health care professionals as well. The stakeholder's awareness and participation in the implementation are vital to provide the necessary resources and the funds. ${ }^{14}$ Various professional organizations need to join hands for the successful implementation of IPE.

\section{Conclusion}

The novel holistic approach to patient care requires interprofessional collaboration. The IPE combines the expertise of various health professions to improve patient outcomes. The inculcation of the IPE from the very beginning in the medical curriculum as a norm will make it easier for the budding doctors to follow it in their future practice. Professional organizations and stakeholders need to accept and promote IPE for the successful implementation of IPE.

\section{References}

1. Institute of Medicine Committee on the Health Professions Education Summit. Health professions education: a bridge to quality. In: Greiner AC, Knebel E, editors. Washington, DC: National Academy Press; 2003.

2. Center for Advancement of Interprofessional Education (CAIPE). Available from: http://www.caipe.org.uk. 
3. Geriatric Interdisciplinary Team Training Program. Available from: https://www.tandfonline.com/doi/abs/10.1300/J021v24n02_02 http://www.gittprogram.org.

4. Buring SM, Bhushan A, Broeseker A, Conway S, Duncan-Hewitt W, Hansen L, et al. Interprofessional education: definitions, student competencies, and guidelines for implementation. Am J Pharm Educ 2009;73(4):59. DOI: 10.5688/aj730459.

5. Freeth D, Hammick M, Reeves S, Koppel I, Barr H. Effective interprofessional education: development, delivery \& evaluation. Oxford, UK: Blackwell Publishing; 2005.

6. Zamanzadeh V, Jasemi M, Valizadeh L, Keogh B, Taleghani F. Effective factors in providing holistic care: a qualitative study. Indian J Palliat Care 2015;21(2):214-224. DOI: 10.4103/09731075.156506.

7. Barr H, Koppel I, Reeves S, Hammick M, Freeth D. Effective interprofessional education: argument, assumption \& evidence. Oxford, UK: Blackwell Publishing; 2005.

8. Accreditation Council for Pharmacy Education. Accreditation standards and guidelines for the professional program in pharmacy leading to the doctor of pharmacy degree; 2006. Available from: https://www.acpe-accredit.org/pdf/ Standards2016FINAL.pdf.

9. Liaison Committee on Medical Education Standards for Accreditation of Medical Education Programs Leading to the M.D. Degree: functions and structure of a medical school; 2007. Available from: https://med.fsu.edu/sites/default/files/userFiles/file/ FacultyDevelopment_Functions_and_Structure_of_a_Medical_ School.pdf.
10. American Association of Colleges of Nursing Essentials of Baccalaureate Education for Professional Nursing Practice. 2008. Available from: https://www.aacnnursing.org/portals/42/ publications/baccessentials08.pdf.

11. Commission on Dental Accreditation, Accreditation Standards for Advanced Education Programs in General Dentistry. 2007. Available from: https://www.ada.org/en/coda/current-accreditationstandards/revised-accreditation-standards

12. Clinical Practice Guidelines on Management of Type 2 DM, 5th ed. 2015. Available from: https://www.moh.gov.my/moh/resources/ Penerbitan/CPG/Endocrine/3a.pdf

13. Berger-Estilita J, Chiang H, Stricker D, Fuchs A, Greif R, McAleer S. Attitudes of medical students towards interprofessional education: a mixed-methods study. PLoS One 2020;15(10):e0240835. DOI: 10.1371/ journal.pone.0240835.

14. Norris J, Carpenter JG, Eaton J, Guo JW, Lassche M, Pett MA, et al. The development and validation of the interprofessional attitudes scale: assessing the interprofessional attitudes of students in the health professions. Acad Med 2015;90(10):1394-1400. DOI: 10.1097/ ACM.0000000000000764.

15. Curran VR, Deacon DR, Fleet L. Academic administrators' attitudes towards Interprofessional education in Canadian schools of health professional education. J Interprof Care 2005;1:76-86. DOI: 10.1080/13561820500081802.

16. Gardner SF, Chamberlin GD, Heestand DE, Stowe CD. Interdisciplinary didactic instruction at academic health centers in United States: attitudes and barriers. Adv Health Sci Educ Theory Pract 2002;7:179190. DOI: $10.1023 / \mathrm{a}: 1021144215376$. 